\title{
Estimation of Bioenergetics Parameters for Rainbow Trout (Oncorhynchus mykiss) Using Capture-Recapture Data with Comparison to Estimates from a Laboratory-Based Model
}

\author{
Brett T. van Poorten* and Carl J. Walters \\ Fisheries Centre, University of British Columbia, Vancouver, B.C. V6T 1Z4, Canada
}

\begin{abstract}
Bioenergetics models provide estimates of growth and consumption in fish and other animals. These estimates can then be used to infer metabolic and population-level consequences of various natural or human-induced environmental perturbations to fish populations. Most existing models utilize parameter values and functions derived from laboratory experiments on similar, closely related populations or species. However, the use of parameters from other species has long been criticized and recent work suggests that certain metabolic rates can vary substantially between closely related species and geographically separated populations of the same species. We evaluate a new model framework (termed the general bioenergetics model) which estimates bioenergetics parameters from length-increment and length-at-age data taken from the same population being modelled. Estimates of growth and consumption from this general model are compared with the commonly used "Wisconsin" bioenergetics model in terms of model fit and predictions resulting from simulated climate warming. Growth estimates using the general bioenergetics model were slightly higher than that of the Wisconsin model but consumption estimates were similar. Both models made similar predictions about effect of climate warming, although there was a consistent difference between model estimates of growth. The findings of this study add weight to the notion that metabolic information through bioenergetics models can be estimated from the population, although further validation should be conducted.
\end{abstract}

Keywords: Bioenergetics, model differences, growth, consumption.

\section{INTRODUCTION}

Bioenergetics models essentially partition consumed food into various fates: somatic and reproductive tissue growth, respiration, egestion and excretion $[1,2]$. These models have been widely used for fish populations [3]. Bioenergetics models typically take information about environmental conditions (i.e. temperature), physiology and consumption or growth and are used to infer unseen consumption from observed size at age, or to predict size at age from estimates of consumption. Estimated lifetime growth and consumption can in turn be used to explain or infer population mortality and growth rates, nutrient flows, and contaminant accumulation rates [1]. Bioenergetics models as applied to fish are commonly used by managers, researchers and policy makers to predict population and ecosystem impacts of various actions such as stocking, harvest, fishing regulation changes, climate change and pollution [4-10].

Several bioenergetics model formulations exist, however the most common are based on Winberg [11] due mostly to its use in the widely available and user-friendly "Wisconsin" model [1]. Bioenergetics models generally and the Wisconsin model specifically have been extensively tested using laboratory [12-14] and field experiments [15-17] as well as by combining several different methods such as growth and contaminant concentrations [18]. However, as with all

*Address correspondence to this author at the Fisheries Centre, University of British Columbia, Vancouver, B.C. V6T 1Z4, Canada; Tel: 604-8220046; Fax: 604-822-8934; Email: b.vanpoorten@ fisheries.ubc.ca models, there are misgivings about bioenergetics models related to parameter uncertainty $[2,19]$ and model structure $[12,20,21]$. One drawback of these models is the use of laboratory estimates from other populations or closely related species as parameter inputs for use in estimating growth and consumption of a population of interest [2]. This parameter "borrowing" largely occurs due to the large number of parameters necessary for most bioenergetics models (12-30+; [22]), which make it extremely difficult to estimate all necessary parameters using laboratory techniques on the same population eventually being modelled. In most circumstances, estimating these parameters in the field is often prohibitively expensive or logistically intractable [15, 23].

When borrowing parameters from other populations or species, it is assumed that there is little variation in parameter values due to genotypic or phenotypic differences between individuals or populations. Recent research on populations of Atlantic silversides (Menidia menidia) from spatially distinct regions showed that several of the physiological rates used in bioenergetics models varied significantly [24]. Even within a population there can be substantial variation in key parameters, which has been shown to result in a wide range of consumption and respiration rates [25]. There is an obvious need to either validate parameter borrowing and choice of parameter estimates in bioenergetics models [26] or put more emphasis on laboratory and field estimates of species- and regional-specific parameter estimates. Clearly, having a model parameterized by the specific population being modelled would be ideal, particularly if parameter estimates are derived from field observations so as to avoid 
issues of differences between field and laboratory behaviour and performance.

A further drawback to most existing bioenergetics models is the lack of admitted uncertainty in both parameter values and model outputs. Some researchers perform sensitivity analyses [3, 27], but rarely is parameter uncertainty incorporated into model estimates. If the model is sensitive to several parameters [28], small population-specific differences in parameter values may result in cumulatively large errors in model predictions and estimates of growth and consumption, which could lead to misleading recommendations.

An alternative to the commonly used approach of using laboratory-derived estimates of parameters to infer growth and consumption from populations in the field is to directly estimate bioenergetics parameters from commonly collected field measurements on growth increments. Walters and Essington [29] have adapted a bioenergetics formulation from Paloheimo and Dickie [30] and incorporated it into a Fabens [30] growth model so it can be fit to lengthincrement data common in mark-recapture studies. These data include length at marking, length at recapture and the time interval between the two events. The model can also be jointly fit to length-at-age data. By estimating parameters directly from field data, there is no need to use unrelated laboratory-based parameter estimates except where parameter effects are confounded in the data. Furthermore, including prior estimates for each parameter along with uncertainty about those prior estimates allows for calculation of a Bayes posterior probability distribution for each parameter, an excellent way to demonstrate parameter uncertainty.

We evaluate the ability of the bioenergetics model formulated in Walters and Essington [29], which will be referred to as the general bioenergetics model, to estimate bioenergetics parameters of a fish population in the field. We also estimate growth and consumption using the popular "Wisconsin" bioenergetics model (Fish Bioenergetics 3.0: [1]), which is largely parameterized using laboratory-based estimates of parameters from the same species or closelyrelated species [16]. Estimates of growth and consumption from the two model-types are compared and the strengths and weaknesses of the field- and laboratory-based models are discussed. To compare predictive abilities, growth and consumption are estimated using each model given warming of water temperatures as would be seen under climate change. Doing so is not meant to provide an accurate estimate of climate change effets, but is used merely as a means of comparing respective predictions from each model. Finally, the merits of each model-type are discussed in light of current and future uses of bioenergetics models.

\section{METHODS}

\section{Data Collection}

Bioenergetics parameters were estimated for rainbow trout (O. mykiss) in Cabin Lake, Alberta, Canada. Cabin Lake is a 32 ha reservoir approximately two $\mathrm{km}$ northwest of the town of Jasper, AB in Jasper National Park. The lake is at $1,217 \mathrm{~m}$ elevation and experiences mean annual water temperatures of $8^{\circ} \mathrm{C}$ and a maximum summer temperature of $18^{\circ} \mathrm{C}$. Complete details of Cabin Lake and the history of this population in the lake can be found in van Poorten and Post [31].

Rainbow trout were sampled between May 2000 and October 2002. In 2000, fish were sampled live using various means: fyke and trap nets, boat mounted electrofisher and angling. In 2001, fish were live-captured exclusively using fyke nets. Each fish captured was anaesthetized and had fork length and weight recorded. Fish with fork length of $150 \mathrm{~mm}$ or greater were tagged using an individually coded spaghetti tag. Recaptured fish were measured, weighed and identified by tag code.

Rainbow trout were also lethally sampled using gillnets in the autumn of all three years. Nets were set mid-day and allowed to fish for approximately 20 hours. On each night, one pelagic and one benthic net was set, where one net consists of one panel each of stretched-mesh sizes $25,32,38$, 51, 64, 76 and $89 \mathrm{~mm}$. This combination of nets has been shown to be size-selective for fish below $120 \mathrm{~mm}$ and largely non-selective for larger fish [32]. Fish captured in gillnets were sampled as above, except otoliths were also removed from all fish for later aging.

Water temperature in the lake was measured using an automated temperature logger deployed at one meter from the surface on the south end of the lake. Temperature was recorded each hour from July 23, 2000 to October 19, 2002. Although water temperature measured near the surface is unlikely to represent the temperatures experienced by individual fish, we assume that the trend in surface temperature is indicative of the trend in temperatures utilized by rainbow trout in the lake.

\section{Bioenergetics Modeling}

Data was fit using the general bioenergetics model presented in Walters and Essington [29]. Specifically, the model incorporated temperature dependence of consumption and metabolism and accounted for dynamic changes in condition factor throughout the year (referred to as the seasonal reproduction, skeletal allocation model; SRSA). Exact formulation of the model and the likelihood function used to fit the model to the data can be found in Walters and Essington [29]. Parameter estimation using the general bioenergetics model was performed in Visual Basic 6.

Daily consumption per gram body weight can be estimated using

$$
C_{t}=\frac{H W_{t}^{d} f_{c}\left(T_{t}\right)}{W_{t} \cdot e \cdot 365}
$$

where $e$ is growth efficiency, calculated as

$$
e=a_{e}(1-S D A) \frac{E_{\text {prey }}}{E_{\text {pred }}} p_{\text {digest }} .
$$

Here, $a_{e}$ is the assimilation efficiency, $S D A$ is the specific dynamic action, $E_{\text {prey }}$ and $E_{\text {pred }}$ are the energy densities of prey and rainbow trout, respectively (Table 2 ) and $p_{\text {digest }}$ is the proportion of the consumed prey that is digestable $(0.9$, [33]). Note that the fitted $H$ parameter is not the laboratory maximum feeding rate per $W^{d}$ at temperature $T_{t}$, but rather 
Table 1. Parameters Used in General Bioenergetics Model. Median Posterior Parameter Estimates are Shown with Uniform Prior Distribution Bounds Shown in Parentheses

\begin{tabular}{|c|c|c|c|}
\hline Parameter & Description & $\begin{array}{l}\text { Median Value } \\
\text { (Prior Bounds) }\end{array}$ & Units \\
\hline$a$ & Intercept coefficient of length-weight relationship & $1.0 \mathrm{e}^{-5}$ & $\mathrm{~g} \mathrm{~mm}^{-\mathrm{b}}$ \\
\hline$b$ & Power coefficient of length-weight relationship & 3.0 & - \\
\hline$H$ & Net food consumption rate per $\mathrm{W}^{-\mathrm{d}}$ & $6.85(1.86-18.61)$ & $\mathrm{g} \mathrm{g}^{-1} \mathrm{yr}^{-1}$ \\
\hline$m$ & Standard metabolic rate per $\mathrm{W}^{-\mathrm{n}}$ & $0.92(0.29-2.89)$ & $\mathrm{g} \mathrm{g}^{-1} \mathrm{yr}^{-1}$ \\
\hline$d$ & Food consumption power parameter & $0.75(0.5-1.0)$ & - \\
\hline$n$ & Metabolism power parameter & $1.03(0.95-1.05)$ & - \\
\hline$Q_{c}$ & Proportional increase in feeding rate per $10^{\circ} \mathrm{C}$ temperature increase & $3.06(1.0-10)$. & - \\
\hline$Q_{m}$ & Proportional increase in metabolism per $10^{\circ} \mathrm{C}$ temperature increase & $2.00(1.90-2.10)$ & - \\
\hline$\theta$ & Slope parameter for decreasing allocation to structural tissue as $W_{s} / W$ varies around $f_{s}^{*}$ & $0.2(0.199-0.20)$ & - \\
\hline$g$ & Steepness parameter for decrease in feeding at high temperatures & 0.25 & ${ }^{\circ} \mathrm{C}^{-1}$ \\
\hline$T_{m}$ & Water temperature at which feeding drops by half & 24 & ${ }^{\circ} \mathrm{C}$ \\
\hline$T_{\max }$ & Maximum water temperature & 17.1 & ${ }^{\circ} \mathrm{C}$ \\
\hline$T_{\text {mean }}$ & Value at inflection point of temperature sine wave & 4.8 & ${ }^{\circ} \mathrm{C}$ \\
\hline$T_{\text {winter }}$ & Mean winter temperature & 3.2 & ${ }^{\circ} \mathrm{C}$ \\
\hline$T_{\Delta}$ & Offset for temperature sine wave & 0.67 & Year \\
\hline$C V_{L}$ & Coefficient of variation of individual maximum body lengths & 0.4 & $\mathrm{~mm}^{2}$ \\
\hline$\sigma_{m}^{2}$ & Measurement variance for $\mathrm{L}_{1}$ and $\mathrm{L}_{2}$ & 64.0 & $\mathrm{~mm}^{2}$ \\
\hline$a_{e}$ & Assimilation efficiency & 0.8 & \\
\hline$\alpha$ & Intercept of the allometric energy density function & 5763 & $\mathrm{Jg}^{-1}$ \\
\hline$\beta$ & Slope of the allometric energy density function & 0.9862 & \\
\hline
\end{tabular}

the product of that maximum rate times the proportion of maximum achieved at time- $t$ (called " $p$ " in the Wisconsin model); variation in field " $p$ " with fish body size and temperature is assumed to be captured in the weight and temperature dependence functions, hence these functions include both physiological (laboratory maximum) and ecological (food availability) effects. With no direct estimate of $e$, we assumed an assimilation efficiency of 0.8 [34], and a SDA of 0.2. Therefore growth efficiency is estimated as $e=0.8 \cdot(1-0.2)^{2619} / E D \cdot 0.9=0.24 . E D$ is the massspecific energy density, defined as $E D=\alpha+\beta W_{t}$, where $\alpha$ and $\beta$ are defined in [33].
The full model was fit to data on length at capture and recapture and intervening time interval, as well as data on length-at-age (complete details of the model and likelihood functions used for fitting are described in Walters and Essington [29]). For each fish that was tagged and subsequently recaptured, only the first and final recapture events were used in parameter estimation, so that each fish was only used once. All fish aged from fall sampling in each of 2000 to 2002 were used in parameter estimation.

When fitting the general bioenergetics model to the tagrecapture data to estimate parameters, we initially attempted to estimate all of the following parameters: $H, d, m, n, Q_{c}$, $Q_{m}, \theta$ (see Table 1). However, as noted in Walters and Essington [29] it is typically not possible to estimate both $d$ 
Table 2. Parameters Used in Wisconsin Bioenergetics Model. Structures of the Indicated Equations can be Found in Hansen et al. [1]

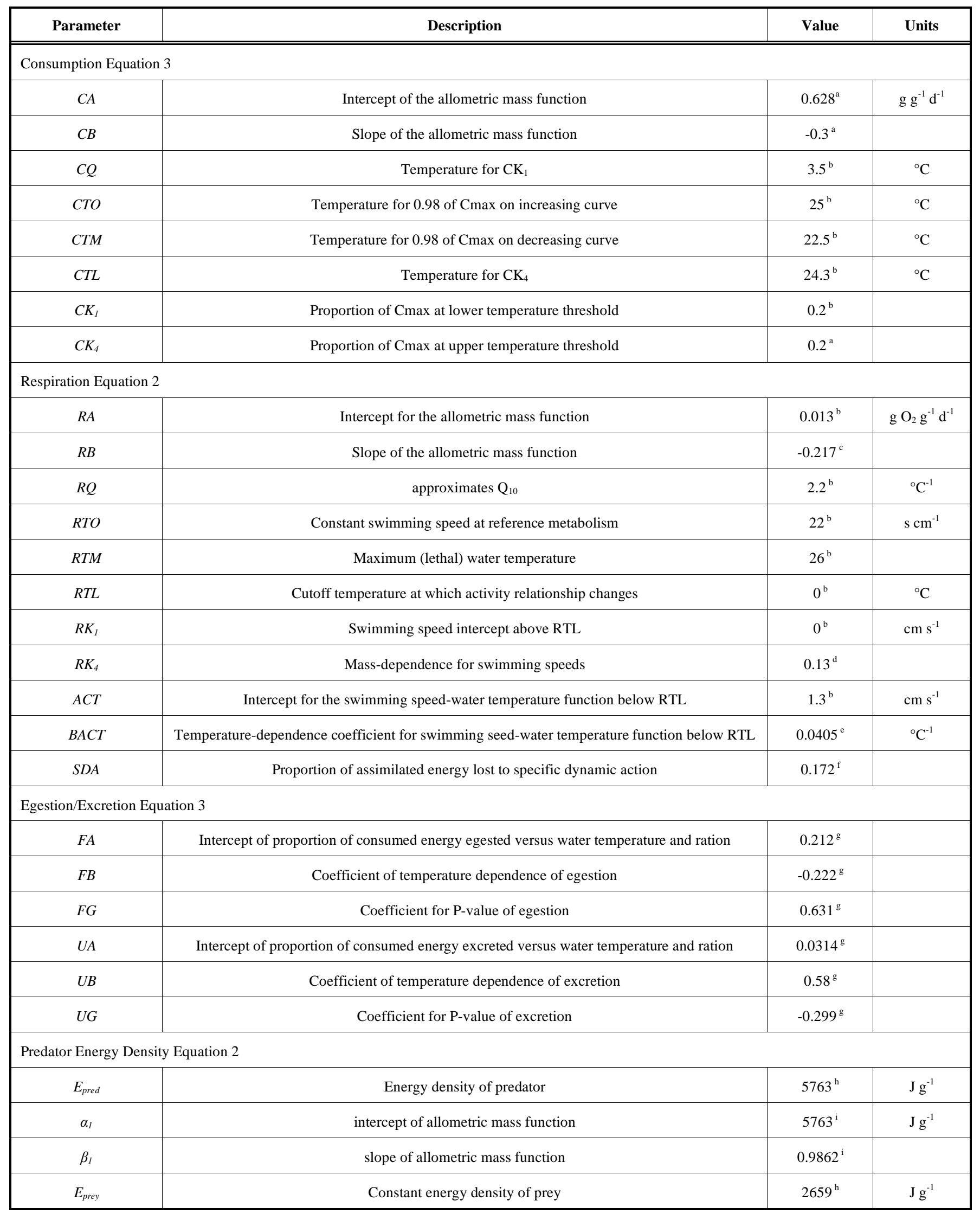

${ }^{\mathrm{a}}[40]$, as cited in [33] ${ }^{\mathrm{b}}[19] ;{ }^{\mathrm{c}}[41,42]$ as cited in [33]; ${ }^{\mathrm{d}}[15]$ as cited in [33]; ${ }^{\mathrm{e}}[43,44]$ as cited in [33]; ${ }^{\mathrm{f}}[33] ;{ }^{\mathrm{g}}[45]$ as cited in [33]; ${ }^{\mathrm{h}}[39] ;{ }^{\mathrm{i}}[1]$ 
and $n$, nor $Q_{c}$ and $Q_{m}$ simultaneously. Initial estimation trials confirmed this, so final trials were performed with the uniform priors on both $n$ and $Q_{m}$ having a limited range (Table 1), i.e. with strong assumptions about size and temperature dependency of metabolic rates. Prior limits were chosen based on findings of $n$ and $Q_{m}$ from Essington et al. [34] and Clarke and Johnston [35], respectively. Additionally, $\theta$ was difficult to estimate, therefore a limited prior was applied to it, similar to that used in Jones et al. [36]. A further simplification involves setting $T_{m}$ and $g$ (water temperature at which feeding drops by half and the rate at which feeding declines as temperatures approach $\mathrm{T}_{\mathrm{m}}$, respectively) much higher than would be observed. As noted in Walters and Essington [29], it is reasonable to assume that temperature never exceeds the optimal for growth, since observed water temperatures are far below this limit. This allows for a reduction in the number of estimated parameters.

Uniform prior distributions were used for each parameter. The posterior density functions were estimated using a Markov-chain Monte Carlo (MCMC) routine [37]. Bounds on the priors for free-ranging parameters were arbitrarily set at 0.3 and 3.0 times the maximum likelihood estimate of each parameter (Table 1). Four MCMC chains were run with different initial values for 500,000 iterations, with a burn-in of 2,000 iterations and further thinned to leave 8,000 samples from each chain. To test for convergence, trace diagrams were visually inspected and the Gelman-Rubin convergence diagnostics were used [37].

Consumption estimated from the general bioenergetics model was compared with that from Bioenergetics 3.0 (referred to as the Wisconsin model; model derivation and description are given in Hansen et al. [1]). Observations of temperature and weight-at-age were input with established parameter values to estimate consumption and growth at each time-step. Parameters for consumption and respiration of rainbow trout were taken from Railsback and Rose [19] and all other parameters are for steelhead from Rand et al. [33]. Mean weight-at-age was obtained from aged fish in the fall sampling in 2000 through 2002 and were fit to a von Bertalanffy growth in weight model. Estimated von Bertalanffy-derived mean weight-at-age was used instead of mean observed weight-at-age because younger ages were not present in sampling gear. Energy density values for rainbow trout and prey were used as model inputs. Rainbow trout energy density was set at $5,861 \mathrm{~J} / \mathrm{g}$ wet weight [38] and prey caloric density was assumed to be a constant $2,659 \mathrm{~J} / \mathrm{g}$ wet weight [39]. Prey of rainbow trout in Cabin Lake entirely consists of terrestrial and aquatic invertebrates, most commonly dipterans, chironomids and amphipods (C.J. MacKenzie, Simon Fraser University, Burnaby, BC, and B.T. van Poorten, unpublished data), which are assumed to be $90 \%$ digestible [19]. All parameters used in the Wisconsin bioenergetics model are shown in Table 2.

Temperature was used in both models to scale consumption and metabolism according by Q10 coefficients. Temperature in Cabin Lake was assumed to follow the same annual cycle throughout the lifetime of all fish in the lake. To this end, a water temperature model was fit to the time-series of measured temperatures from Cabin Lake (Fig. 1). The temperature model is based on a sine-wave with a minimum winter temperature and took the form

$$
T_{t}=\max \left[T_{\text {winter }}, T_{\text {mean }}+\left(T_{\text {max }}-T_{\text {mean }}\right) \sin \left(\left(t+t_{\Delta}\right)\right) \cdot 2 \pi\right]
$$

where $T_{t}$ is the temperature at time $t, t_{\Delta}$ is an offset in the sine wave to ensure the peak coincided with summer temperatures, and $T_{\max }, T_{\min }$, and $T_{\text {winter }}$ are the minimum and maximum temperatures of the sine wave and mean winter temperature, respectively.

Both the general and Wisconsin bioenergetics models require information on timing of maturity and proportion of mass devoted to reproduction. Mean mass-at-maturity, used in the general model, was estimated by fitting a logistic model to the proportion of mature fish for each $10 \mathrm{~mm}$ size bin captured in fall sampling. Mean age-at-maturity, used in the Wisconsin model, was estimated by fitting a logistic model to the proportion of mature fish for each age-class captured in the fall sampling. Mass- and age-at-maturity were estimated as the mass or age at which $50 \%$ of individuals are mature. It was assumed that $15 \%$ of available body mass is lost during spawning [46]. Spawning date for the population was set as June 1 (B. van Poorten, unpublished data), hatch date was set as July 15 and length at hatch was set as $18 \mathrm{~mm}$ [47]. All parameter values used in the general bioenergetics model are shown in Table $\mathbf{1}$.

\section{Evaluating Growth Predictions with Climate Change}

Bioenergetics models are commonly used to predict impacts of changes in species composition or temperature regimes on fish growth, mortality, consumption or nutrient cycling (see $[1,12]$ for examples). To compare the general and Wisconsin bioenergetics models, we examined simulated impacts of climate change on rainbow trout growth using both the general and Wisconsin bioenergetics models. To do so, we increased water temperatures input into each model. Doing so is not meant to be an accurate prediction of climate change impacts, but simply a means of comparing simulated outcomes of the two models. In each model, the parameters $T_{\min }$ and $T_{\max }$ in Equation 3 were increased by a value of 3 (Fig. 1). This results in an increase of mean annual water temperature of $1.7^{\circ} \mathrm{C}$ and an increase in the number of ice-free days from 197 to 226 . The daily temperature calculated using Equation 3 was then applied to both bioenergetics models to examine the predictions made by each model.

To estimate size-at-age and consumption using the general bioenergetics model assuming a temperature increase expected with climate change, the posterior distribution of parameter estimates based on the observed data in Cabin Lake were resampled 5,000 times. The resampled parameter estimates in association with the climate warming annual temperature cycle provided the size-at-age and consumption for rainbow trout in Cabin Lake. Using the Wisconsin model, simulations were repeated with the warmed annual temperature cycle assuming the proportion of maximum feeding estimated above. These model simulations assume that prey availability increases at the same rate as maximum potential consumption. 


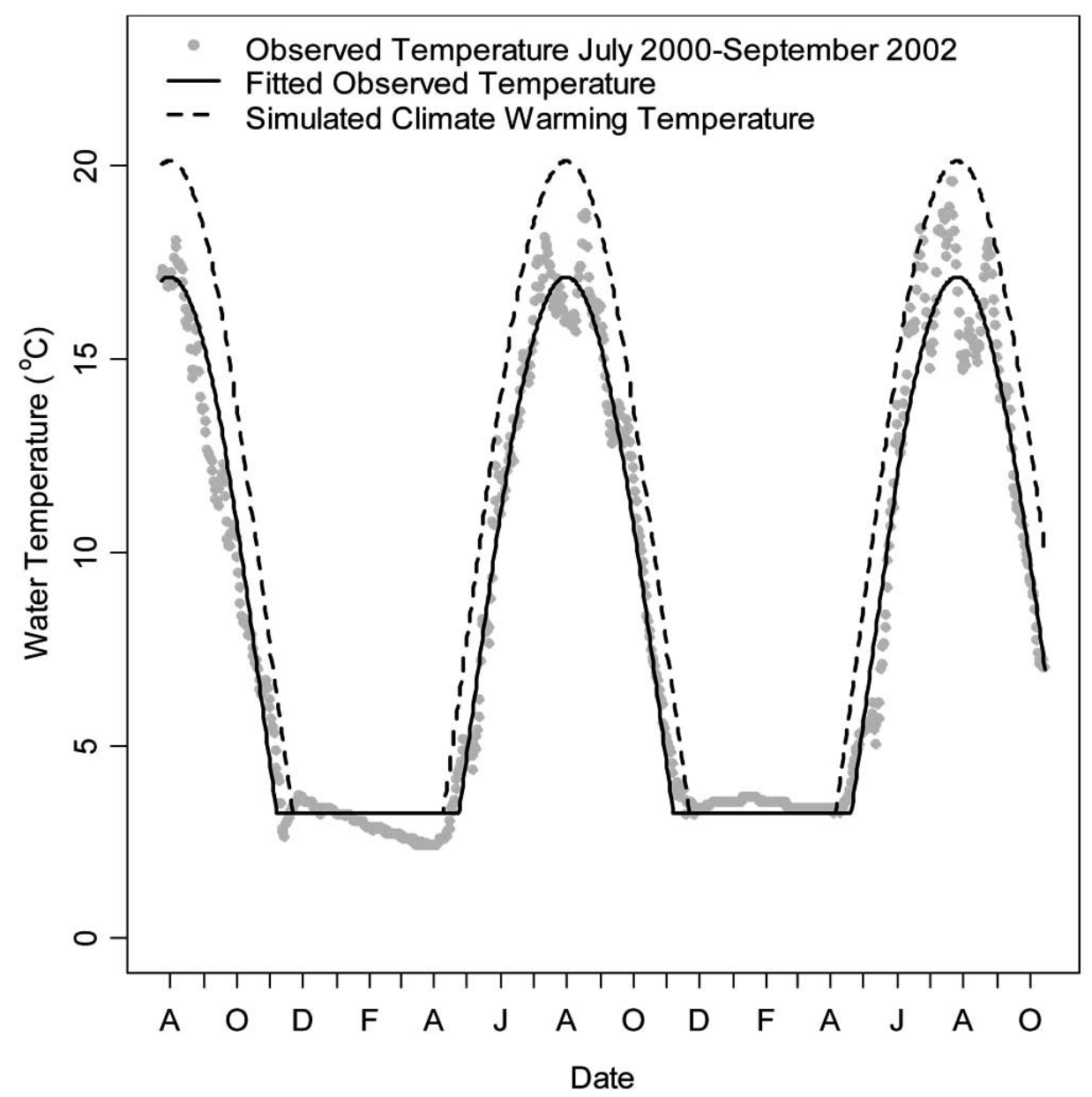

Fig. (1). Observed temperature in Cabin Lake, Alberta between July 2000 and September 2002 (light dots). Solid line represents fitted temperature model used in both bioenergetics estimates of growth and consumption. Dashed line represents theoretical temperature model under climate change used in both bioenergetics simulations of growth and consumption under climate change.

\section{RESULTS}

In total, 668 rainbow trout from Cabin Lake were captured and later recaptured. Of these, five records were removed due to obvious misidentification of fish or measurement errors (length decrease of $>10 \mathrm{~mm}$ ) and five were removed because fish were recaptured in the same day. Of the remaining 658 length-increment records, 425 were measured within the same year, 230 were measured over one winter and three were measured over two winters. Additionally, 520 rainbow trout were captured and aged in the fall sampling in 2000 to 2002.

The general bioenergetics model was fit to length increment and length-at-age data to estimate bioenergetics parameters of the Cabin Lake population between 2000 and 2002. Prior limits to the metabolism power parameter $(n)$, the $Q_{10}$ parameter related to metabolism $Q_{m}$, and $\theta$ (the rate at which tissue is diverted to structural tissue as weight at length approaches normal) were intentionally set with a narrow range because parameter effects were confounded in the data. All other prior distributions were uninformative and yet, most posteriors were well defined indicating that data were informative about the values of the parameters allowed to freely vary (Fig. 2).
The general bioenergetics model was fit to length increment and length-at-age data in order to estimate a complete growth trajectory for rainbow trout in the population (Fig. 3). Comparing the estimated weight-at-age with observed weight-at-age shows the model estimated weight-at-age well despite the model being fit only to observed lengths.

Compared with the predicted size-at-age from the general model, the Wisconsin model estimate was generally lower (Fig. 4A), which is likely due to the weight-at-age estimated using the von Bertalanffy model rather than both the size-atage and length-increment data. Additionally, the Wisconsin model predicts that rainbow trout lose weight through the winter after age-2, which the general model does not. Median consumption estimated using the general bioenergetics model was similar to that estimated using the Wisconsin bioenergetics model (Fig. 4B). Over the lifetime of a rainbow trout in Cabin Lake, the median consumption estimate from the general bioenergetics model ranged from $75 \%$ to $141 \%$ that of the Wisconsin consumption estimate. Direct estimates of consumption are not available for the rainbow trout of Cabin Lake and so corroboration of either model is not possible. 

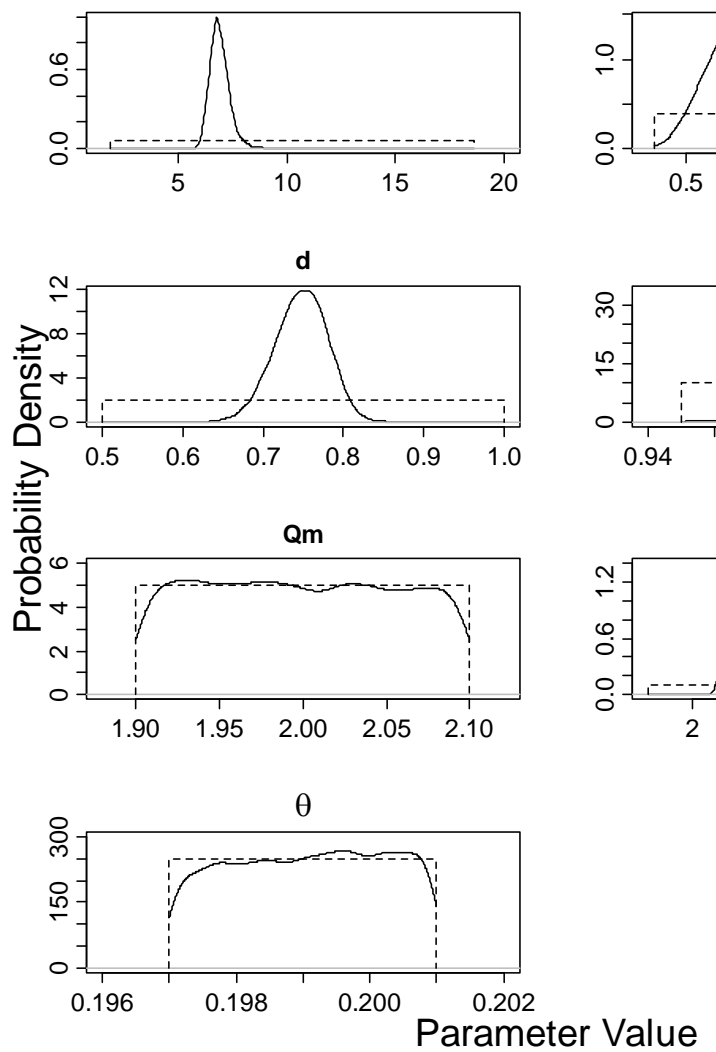

m

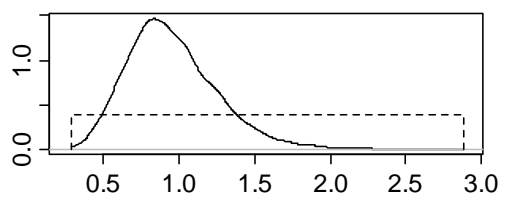

n

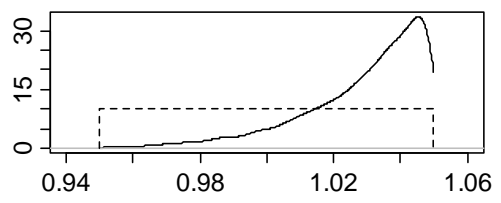

Qc

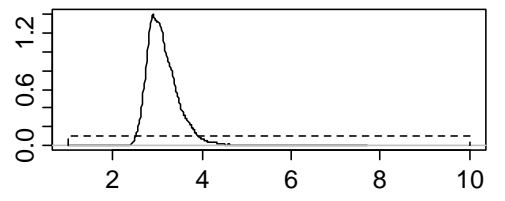

Fig. (2). Prior and posterior probability densities for the four general bioenergetics parameters $(H, m, d$ and $n)$ relating to consumption and metabolism, the two $Q_{10}$ parameters $\left(Q_{m}\right.$ and $\left.Q_{c}\right)$ which scale consumption and metabolism as a function of temperature and $\theta$, which varies allocation of structural tissue relative to changes in the ratio of structural to total weight from $\mathrm{f}_{\mathrm{s}}{ }^{*}$. Densities are Gausian smoothed approximations. Prior probability density functions are dashed lines and posterior probability densities are solid lines.
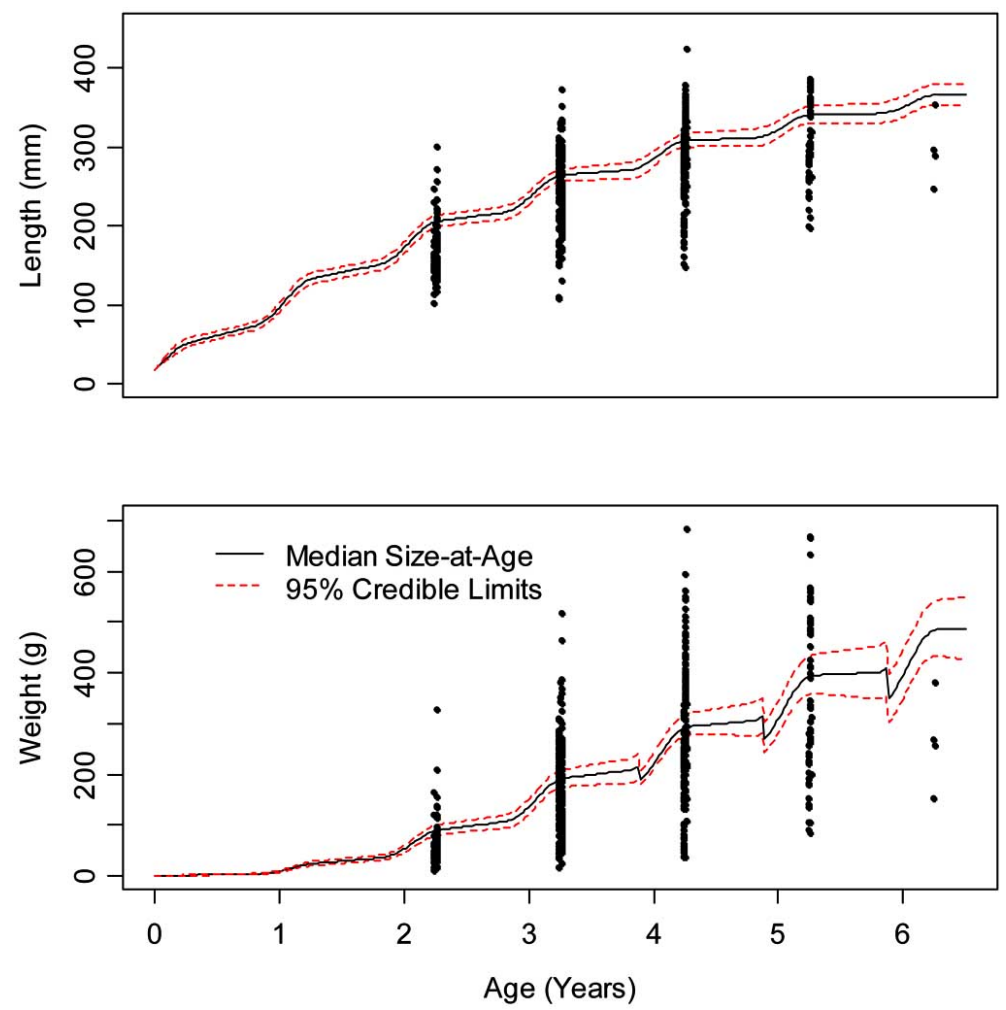

Fig. (3). Observed length-at-age (points; top panel) and weight-at-age (points; bottom panel) of rainbow trout captured in Cabin Lake in autumn 2000 to 2002 and estimated length- and weight-at-age estimated by general bioenergetics model (solid line). Dashed lines represent Bayesian posterior $95 \%$ credible limits. 

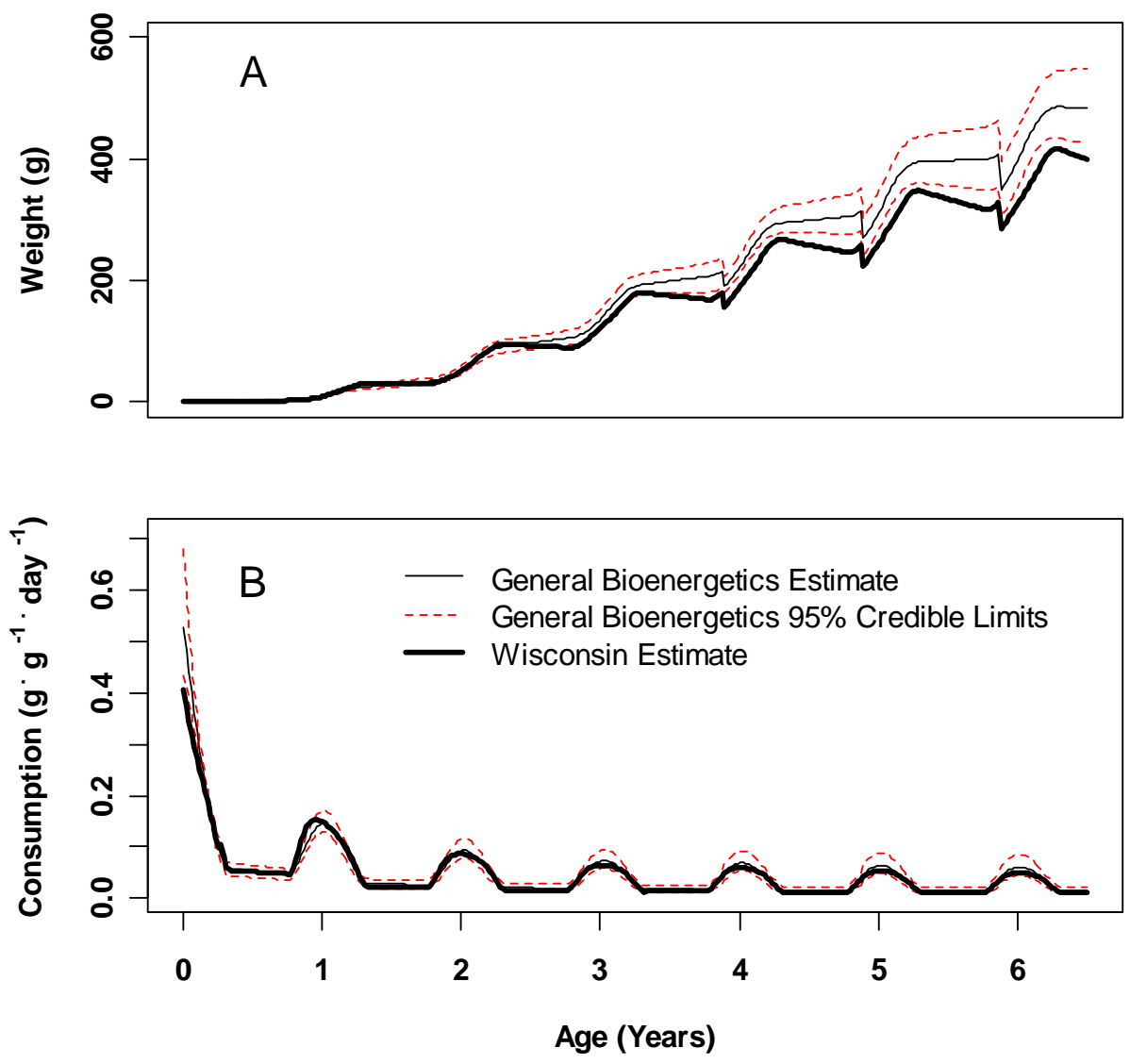

Fig. (4). Weight-at-age (top panel) and daily consumption (bottom panel) for rainbow trout estimated using the general bioenergetics model (thin line) and the Wisconsin bioenergetics model (bold line). Dashed lines indicate Bayesian posterior $95 \%$ credible limits of general model estimate.

When both models were used to estimate the impact increased water temperatures will have on growth, both models predicted increases in size (Fig. 5A). The Wisconsin bioenergetics model estimated an increase in end mass from 417 $\mathrm{g}$ to $518 \mathrm{~g}$ when simulated temperature in the lake increased due to climate warming. In contrast, the general bioenergetics model estimated the end mass increasing from $564 \mathrm{~g}$ to $787 \mathrm{~g}$. The difference in growth is approximately proportional to that observed with the fitted model. Median daily estimated consumption from the general bioenergetics model ranged from $67 \%$ to $147 \%$ the consumption estimated using the Wisconsin model (Fig. 5B). This again is similar to the difference in consumption rate estimates for the two models.

\section{DISCUSSION}

The general bioenergetics model was able to fit to lengthat-age and length-increment data to estimate growth and consumption for rainbow trout in Cabin Lake. Laboratory data may be used to provide prior probability distributions for some parameters, and this was necessary in fitting the general bioenergetics model to the relatively small Cabin Lake data set. Our estimation used informative prior distributions on only three parameters: the metabolism power parameter, $n$, the $Q_{10}$ parameter for metabolism, $Q_{m}$, and the steepness parameter $(\theta)$ associated with the rate at which consumed nutrients are allocated to metabolizeable tissue as the ratio of metabolizeable to total weight decreases below the optimum. While we had limited prior information available to apply to the model, future rainbow trout models can incorporate our posterior probability distributions as prior probability distributions, thereby further refining future models for situations where data are relatively uninformative [48]. Other datasets are likely to have varying success at fitting more or fewer parameters [29] based on both the quantity of data and the variability in temperature and feeding environments throughout the lifetime of the fish.

Some parameters are not estimable and use of laboratorybased estimates or reasonable approximations are necessary to run the general bioenergetics model. These include the parameters related to consumption and skeletal allocation. While consumption parameters are not directly used in the estimation procedure for key bioenergetics parameters, they play a key role in estimating consumption and therefore have implications for trophic interactions derived from model outcomes. We have not directly estimated these parameters, however it is advisable for future applications. Skeletal allocation parameters are directly used during parameter estimation in the general bioenergetics model and may influence final parameter estimates. In populations such as the one modelled here, changes in condition factor throughout the lifetime of a fish are minimal. In other populations it will be important to investigate the variability in condition factor 

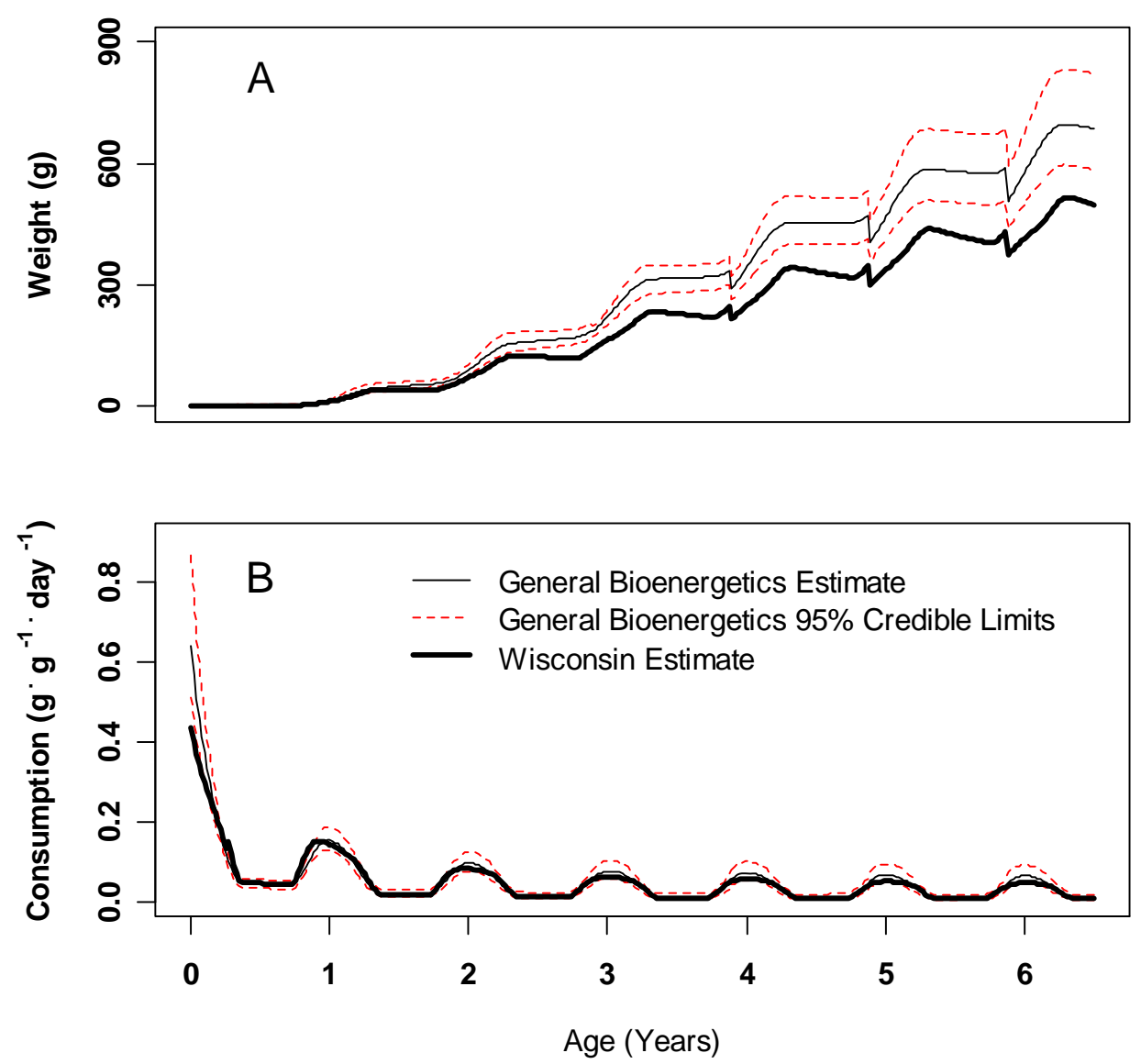

Fig. (5). Weight-at-age (upper panel) and daily consumption (lower panel) for rainbow trout in warmed water simulated using the general bioenergetics model (thin line) and the Wisconsin bioenergetics model (bold line). Dashed lines indicate Bayesian posterior 95\% credible limits of general model estimate.

over the life of a fish and those populations with considerable changes in condition factor should carefully examine how skeletal allocation parameters affect other parameter estimates.

Both the general and Wisconsin bioenergetics models were able to reconstruct the growth history of Cabin Lake rainbow trout using data from 2000 to 2002 . Interestingly, the growth estimate for the general model was higher than that based on the Wisconsin model. This is partially due to patterns in the length-increment data used in fitting the general model, in addition to the size-at-age data used by both models. Use of size-increment data in the general bioenergetics model means that the model estimate of growth rate as a function of size and temperature is more precisely defined from the data than for the Wisconsin model, which is driven by mean size-at-age data only.

The Wisconsin model estimated an over-winter decline in body mass, whereas the general bioenergetics model did not. Observed weight-increment data from tagged fish suggest that rainbow trout rarely lose weight over the winter between observations in fall and the following spring (B. van Poorten, unpublished data). Both of the models used here assume a constant seasonal energy density in both predators and prey, which is rarely, if ever, true. Seasonal changes in diet will doubtlessly result in changes in energy consumption [49] and predator energy density [50]. Additionally, as winter conditions continue, mass may stay relatively constant while energy density declines due to an increase in water content and decrease in whole-body energy density [51, 52]. These factors would help to reduce the discrepancy in over-winter loss in body mass between the two models and would contribute to a slight variation in estimates of over-winter consumption in the general bioenergetics model.

The general bioenergetics consumption estimate was similar to that of the Wisconsin model. Several studies have shown that the Wisconsin model has difficulty estimating consumption across a range of taxa [29]. Although no direct study of rainbow trout has been made, consumption in salmonids is often overestimated in the Wisconsin model [53]. The Wisconsin model estimates consumption by multiplying a laboratory-derived function of maximum consumption rate at body size and temperature by a proportion ( $p$-value) to back-calculate observed growth. $P$-values estimated with our Wisconsin model (range: $0.505-0.534$ ) for age-1 to 7 were higher than estimated in other models [19]. This may be due to a number of factors, including temperature time series is not indicative of what was actually experienced by most trout in the population or prey and predator energy densities being inaccurate and constant throughout the year, despite this often not being true $[49,50,54]$. Corroboration of model outcomes with field or laboratory estimates are important for 
bioenergetics models $[3,16,18,28]$ and the same holds true for the general model. Future corroboration of various components of the general bioenergetics model will be necessary to further examine the utility of this new tool.

We recognize that simply increasing temperature is an extreme oversimplification of potential effects of climate change on freshwater fish $[5,55,56]$. It is widely recognized that with increased water temperatures, there will not be a simple proportional increase in biomass, but complex changes in nutrient flows, behaviour, abundance of food organism populations, and species-specific differences in consumption and activity, among many other complications [5659]. The purpose of the climate-change simulation was not to make accurate predictions of potential impacts, but rather to contrast the predictions of the two models that make more or less use of field data from the study system. The relative difference in growth and consumption predictions for the two models does not appreciably change when the water is warmed.

There are a large number of parameters that may be used in bioenergetics models (e.g. 12-30+: [1, 2]), which can potentially lead to more detailed estimates and the ability to attribute expected changes in consumption and metabolic rates into one of several specific bioenergetic rates or processes. However, Ney [22] demonstrated that similar results can be gained with a simpler model structure. Using a model of intermediate complexity, we have estimated similar growth trajectories and are able to predict future outcomes under a simple climate-warming scenario. Slight additions to the general bioenergetics model could allow it to make additional predictions similar to those commonly made with the Wisconsin model [1, 3, 28]. For example, contaminant concentrations, ecosystem models and management evaluations could easily incorporate the general bioenergetics model with minimal data needs. Furthermore, the Bayesian parameter estimation allows uncertainty in parameter estimates to be incorporated into management recommendations, in a decision analysis framework [60]. The Wisconsin model has a long history of predicting and evaluating individual and population responses to a wide variety of manipulations [3]. The ability of the general model to be fit to populationspecific data and incorporate parameter uncertainty should make it a powerful new tool in the continued use of bioenergetics models in fisheries research and management.

The purpose of this paper was not to reveal weaknesses of one method or another but merely to compare estimates and discuss possible reasons for any divergent estimates. Qualitatively, it appears that both models evaluated here provide similar outcomes. We recognize that bioenergetics models in general are prone to inaccuracies $[2,53]$ due both to parameter uncertainties and structural problems. The general bioenergetics model of Walters and Essington [29] addresses one of these issues by estimating parameters directly from field length increment and length-at-age data commonly collected in many population assessments. Overall, the model proposed by Walters and Essington [29] provides an alternative to the Wisconsin model, with estimation of at least some parameter values directly from the population being modelled, thereby providing a useful option for future applications.

\section{ACKNOWLEDGEMENTS}

Data collection from Cabin Lake was achieved through funding by Challenge Grants in Biodiversity from the Alberta Conservation Association and by Parks Canada. B.v.P. was supported during analysis and manuscript preparation by a NSERC Postgraduate Scholarship. This manuscript was greatly improved by comments and suggestions from an anonymous reviewer.

\section{REFERENCES}

[1] Hanson PC, Johnson TB, Schindler DE, Kitchell JE. Fish Bioenergetics 3.0. Madison, WI: University of Wisconsin, Sea Grant Institute; 1997. Report No.: No. WISCU-T-97-001.

[2] Ney JJ. Bioenergetics modeling today: growing pains on the cutting edge. Trans Am Fish Soc 1993; 122: 736-48.

[3] Hartman KJ, Kitchell JE. Bioenergetics modeling: Progress since the 1992 symposium. Trans Am Fish Soc 2008; 137: 216-23.

[4] Perry WB, Janowsky WA, Margraf FJ. A bioenergetics simulation of the potential effects of angler harvest on growth of Largemouth Bass in a catch-and-release fishery. North Am J Fish Manage 1995; 15: 705-12.

[5] Rose KA, Megrey BA, Hay D, Werner F, Schweigert J. Climate regime effects on Pacific herring growth using coupled nutrientphytoplankton-zooplankton and bioenergetics models. Trans Am Fish Soc 2008; 137: 278-97.

[6] Jones ML, Koonce JF, O'Gorman R. Sustainability of hatcherydependent salmonine fisheries in Lake Ontario: the conflict between predator demand and prey supply. Trans Am Fish Soc 1993; 122: 1002-18.

[7] Hill DK, Magnuson JJ. Potential effects of global climate warming on growth and prey consumption of Great Lakes fish. Trans Am Fish Soc 1990; 119: 265-75.

[8] Petersen JH, Kitchell JE. Climate regimes and water temperature changes in the Columbia River: bioenergetic implications for predators of juvenile salmon. Can J Fish Aquat Sci 2001; 58: 183141.

[9] Paukert CP, Petersen JH. Comparative growth and consumption potential of rainbow trout and humpback chub in the Colorado River, Grand Canyon, Arizona, under different temperature scenarios. Southwest Nat 2007; 52: 234-42.

[10] Coghlan SMJ, Ringler NH. Survival and bioenergetic responses of juvenile Atlantic salmon along a perturbation gradient in a natural stream. Ecol Fresw Fish 2005; 14: 111-24.

[11] Winberg GG. Rate of metabolism and food requirements of fishes. Fisheries Research Board of Canada Translation Series: Ottawa 1956.

[12] Bajer PG, Whitledge GW, Hayward RS, Zweifel RD. Laboratory evaluation of two bioenergetics models applied to yellow perch: identification of a major source of systematic error. J Fish Biol 2003; 62: 463-54.

[13] Chipps SR, Einfalt LM, Wahl DH. Growth and food consumption by tiger muskellunge: effects of temperature and ration level on bioenergetic model predictions. Trans Am Fish Soc 2000; 129: 186-93.

[14] Hartman KJ, Brandt SB. Systematic sources of bias in a bioenergetics model: examples for age-0 striped bass. Trans. Am Fish Soc 1993; 122: 912-26.

[15] Beauchamp DA, Stewart DJ, Thomas GL. Corroboration of a bioenergetics model for sockeye salmon. Trans Am Fish Soc 1989; 118: 597-607.

[16] Boisclair D, Sirois P. Testing assumptions of fish bioenergetics models by direct estimation of growth, consumption and activity rates. Trans Am Fish Soc 1993; 122: 784-96.

[17] Rice JA, Cochran PA. Independent evaluation of a bioenergetics model for largemouth bass. Ecology 1984; 65: 732-39.

[18] Madenjian CP, O'Connor DV, Nortrup DA. A new approach toward evaluation of fish bioenergetics models. Can J Fish Aquat Sci 2000; 57: 1025-32.

[19] Railsback SF, Rose KA. Bioenergetics modeling of stream trout growth: temperature and food consumption effects. Trans Am Fish Soc 1999; 128: 241-56. 
[20] Bajer PG, Whitledge GW, Hayward RS. Widespread consumptiondependent systematic error in fish bioenergetics models and its implications. Can J Fish Aquat Sci 2004; 61: 2158-67.

[21] Bajer PG, Hayward RS, Whitledge GW, Zweifel RD. Simultaneous identification and correction of systematic error in bioenergetics models: demonstration with a white crappy (Pomoxis annularis) model. Can J Fish Aquat Sci 2004; 61: 2168-82.

[22] Ney JJ. Trophic economics in fisheries: assessment of demandsupply relationships between predators and prey. Rev Aquat Sci 1990; 2: 55-81.

[23] Lucas MC, Johnstone ADF, Priede IG. Use of physiological telemetry as a method for estimating metabolism of fish in the natural environment. Trans Am Fish Soc 1993; 122: 822-33.

[24] Munch SB, Conover DO. Accounting for local physiological adaptation in bioenergetic models: testing hypotheses for growth rate evolution by virtual transplant experiments. Can J Fish Aquat Sci 2002; 59: 393-403.

[25] Tyler JA, Bolduc MB. Individual variation in bioenergetic rates of young-of-year rainbow trout. Trans Am Fish Soc 2008; 137: 31423.

[26] Brandt SB, Hartman KJ. Innovative approaches with bioenergetics models: future applications to fish ecology and management. Trans Am Fish Soc 1993; 122: 731-35.

[27] Rowan DJ, Rasmussen JB. Measuring the bioenergetic cost of fish activity in situ using a globally dispersed radiotracer $\left({ }^{137} \mathrm{Cs}\right)$. Can J Fish Aquat Sci 1996; 53: 734-45.

[28] Hansen LJ, Boisclair D, Brandt SB, Hewett SW, Kitchell JE, Lucas MC, et al. Applications of bioenergetics models to fish ecology and management: where do we go from here? Trans Am Fish Soc 1993; 122: 1019-30.

[29] Walters C, Essington TE. Recovery of bioenergetics parameters from information on growth. Open Fish Sci J 2010; 3: 52-68.

[30] Paloheimo JE, Dickie LM. Food and growth of fishes. I. A growth curve derived from experimental data. J Fish Res Board Can 1965; 22: 521-42.

[31] van Poorten BT, Post JR. Seasonal fishery dynamics of a previously unexploited rainbow trout population with contrasts to established fisheries. North Am J Fish Manage 2005; 25: 329-45.

[32] Askey PJ, Post JR, Parkinson EA, Rivot E, Paul AJ, Biro PA. Estimation of gillnet efficiency and selectivity across multiple sampling units: A hierarchical Bayesian analysis using mark-recapture data. Fish Res 2007; 83: 162-74.

[33] Rand PS, Stewart DJ, Seelbach PW, Jones ML, Wedge LR. Modeling steelhead population energetics in Lake Michigan and Ontario. Trans Am Fish Soc 1993; 122: 977-1001.

[34] Essington TE, Kitchell JF, Walters CJ. The von Bertalanffy growth function, bioenergetics, and the consumption rates of fish. Can J Fish Aquat Sci 2001; 58: 2129-38.

[35] From J, Rasmussen G. A growth model, gastric evacuation, and body composition in rainbow trout, Salmo gairdneri Richardson, 1836. Dana 1984; 3: 61-139.

[36] Rao GMM. Oxygen consumption of rainbow trout (Salmo gairdneri) in relation to activity and salinity. Can J Zool 1968; 46: 781-86.

[37] Rao GMM. Influence of activity and salinity on the weightdependent oxygen consumption of the rainbow trout Salmo gairdneri. Mar Biol 1971; 8: 205-12.

[38] Griffiths JS, Alderdice DF. Effects of acclimation and acute temperature experience on the swimming speed of juvenile coho salmon. J Fish Res Board Can 1972; 29: 251-64.
[39] Glova GJ, McInerney JE. Critical swimming speeds of coho salmon (Oncorhynchus kisutch) fry to smolt stages in relation to salinity and temperature. J Fish Res Board Can 1977; 34: 151-54.

[40] Elliott JM. Energy losses in the waste products of brown trout (Salmo trutta L.). J Anim Ecol 1976; 45: 561-80.

[41] Cummins KW, Wuycheck JC. Caloric equivalents for investigations in ecological energetics. Verh Int Ver Theor Angew Limnol 1971; 18: 1-158.

[42] Clark A, Johnston NM. Scaling of metabolic rate with body mass and temperature in teleost fish. J Anim Ecol 1999; 68: 893-995.

[43] Jones W, Gurney WSC, Speirs DC, Bacon PJ, Youngson AF. Seasonal patterns of growth, expenditure and assimilation in juvenile Atlantic salmon. J Anim Ecol 2002; 71: 916-24.

[44] Gelman A, Carlin JB, Stern HS, Rubin DB. Bayesian Data Analysis. New York: Chapman and Hall 1995.

[45] Bryan SD, Soupir CA, Duffy WG, Frieburger CE. Caloric densities of three predatory fishes and their prey in Lake Oahe, South Dakota. J Fresh Ecol 1996; 11: 153-61.

[46] Jobling M. Environmental Biology of Fishes. London, UK: Chapman and Hall; 1995.

[47] Ellis RJ, van den Heuvel MR, Smith MA, Ling N. Effects of maternal versus direct exposure to pulp and paper mill effluent on rainbow trout early life stages. J Toxicol Environ Health 2005; 68: 369-87.

[48] McCarthy MA. Bayesian Methods for Ecology. Cambridge: Cambridge University Press 2007.

[49] Cunjak RA, Power G. The feeding and energetics of streamresident trout in winter. J Fish Biol 1987; 31: 493-511.

[50] Jonas JL, Kraft CE, Margenau TL. Assessment of seasonal changes in energy density and condition in age-0 and age-1 muskellunge. Trans Am Fish Soc 1996; 125: 203-10.

[51] Post JR, Parkinson EA. Energy allocation strategy in young fish: allometry and survival. Ecology 2001; 82: 1040-51.

[52] Gardiner WR, Geddes P. The influence of body composition on the survival of juvenile salmon. Hydrobiologia 1980; 69: 67-72.

[53] Chipps SR, Wahl DH. Bioenergetics modeling in the 21st century: Reviewing new insights and revisiting old constraints. Trans Am Fish Soc 2008; 137: 298-313.

[54] Foy RJ, Paul AJ. Winter feeding and changes in somatic energy content of age-0 Pacific herring in Prince William Sound, Alaska. Trans Am Fish Soc 1999; 128: 1193-200.

[55] Ficke AD, Myrick CA, Hansen LJ. Potential impacts of global climate change on freshwater fisheries. Rev Fish Biol Fish 2007; 17: 581-613.

[56] DeStasio BT, Hill DK, Klenhans JM, Nibelink NP, Magnuson JJ. Potential effects of global climate change on small north-temperate lakes: physics, fish, plankton. Limnol Oceanogr 1996; 41: 1136-49.

[57] Biro PA, Post JR, Booth DJ. Mechanisms for climate-induced mortality of fish populations in whole-lake experiments. Proc Natl Acad Sci USA 2007; 104: 9715-19.

[58] Roessig JM, Woodley CM, Cech JJ, Hansen LJ. Effects of global climate change on marine and estuarine fishes and fisheries. Rev Fish Biol Fish 2005; 14:251-75.

[59] Schindler DW. Widespread effects of climate warming on freshwater ecosystems in North America. Hydrol Processes 1997; 11: 1043-67.

[60] Walters CJ, Martell SJD. Fisheries Ecology and Management: Princeton University Press, 2004.

[61] Stewart DJ, Ibarra M. Predation and production by salmonine fishes in Lake Michigan 1978-88. Can J Fish Aquat Sci 1991; 48: 909-22.

(C) van Poorten and Walters; Licensee Bentham Open.

This is an open access article licensed under the terms of the Creative Commons Attribution Non-Commercial License (http://creativecommons.org/licenses/by-nc/3.0/) which permits unrestricted, non-commercial use, distribution and reproduction in any medium, provided the work is properly cited. 